\title{
DOCÊNCIA NA CIBERCULTURA: RELATOS DE UMA EXPERIÊNCIA EXTENSIONISTA
}

\section{TEACHING IN CYBERCULTURE: REPORTS OF AN OUTREACH EXPERIENCE}

\author{
Grazielle de Souza Brandão* \\ ORCID: https://orcid.org/0000-0003-3488-5559 \\ Juliana Brandão Machado** \\ ORCID: https://orcid.org/0000-0003-0181-317X
}

\section{Resumo}

O projeto de extensão "O trabalho docente na Cibercultura: reflexões sobre a docência na cultura digital", realizado em 2018, surgiu a fim de problematizar a inclusão de tecnologias digitais na prática pedagógica, contemplando os estudantes de licenciatura do campus Jaguarão-RS e egressos de licenciatura e professores da Educação Básica. Teve por objetivos refletir sobre a inclusão de recursos tecnológicos digitais na sala de aula, buscando alternativas de mudança na prática pedagógica e aprofundamento na discussão acerca da temática e sua relação com a educação. A metodologia se deu inicialmente por meio de leituras de autoras como Santaella (2013) e Santos (2015); em seguida, a criação de oficinas a partir das demandas do grupo participante, a fim de constituir aprofundamento teórico referente aos conceitos de Cibercultura na formação docente. O projeto oportunizou aos estudantes uma discussão fundamental sobre a importância das tecnologias digitais nas escolas como fortes aliadas da educação.

Palavras-chave: Cibercultura; Trabalho docente; Formação de professores; Tecnologias digitais.

\begin{abstract}
The outreach project "Teachers' work in cyberculture: reflections on teaching in the digital culture" carried out in 2018, emerged in order to discuss the inclusion of digital technologies in pedagogical practice, including undergraduate students of the Jaguarão -RS campus and also undergraduate graduates and teachers of Basic Education. It aimed to reflect about the inclusion of digital technological resources in the classroom, searching for alternatives to change pedagogical practice and deepen the discussion about the theme and its relation with education. The methodology involved initially readings of authors such as Santaella (2013) and Santos (2015) followed by the creation of workshops based on the demands of the participating group in order to build a sound theoretical support related to the concepts of Cyberculture in teacher education. The project provided students with the opportunity for an essential discussion about the importance of digital technologies in schools as strong allies for education.
\end{abstract}

Keywords: Cyberculture; Teaching work; Teacher education; Digital technologies. 


\section{Introdução}

O objetivo deste artigo é apresentar as atividades do Projeto de Extensão "O trabalho docente na Cibercultura: reflexões sobre a docência na cultura digital", realizado no ano de 2018, na UNIPAMPA, Campus Jaguarão, e discutir sobre a formação docente para a cibercultura. Este projeto surgiu em continuidade ao projeto desenvolvido em 2017, uma formação continuada ofertada aos docentes do município de Jaguarão/RS, que problematizou a inclusão de tecnologias digitais na prática pedagógica. Em vista da baixa adesão por parte dos professores das redes de ensino municipal e estadual, pensou-se em uma nova proposta para o ano seguinte, contemplando também os egressos e os estudantes de licenciatura da UNIPAMPA.

O projeto teve por objetivos problematizar o trabalho docente na cultura digital, refletir sobre a inclusão de recursos tecnológicos digitais na sala de aula, buscando alternativas de mudança na prática pedagógica, e aprofundar a discussão acerca da temática e sua relação com a educação.

Conforme mencionado no parágrafo anterior, este projeto foi realizado no ano de 2018, momento em que os encontros eram presenciais, pois a partir do ano de 2020, com a pandemia de Covid-19, todas as atividades passaram a acontecer de forma remota. Os relatos sobre essa experiência vão ao encontro das necessidades e dos desafios ocasionados à educação neste contexto, principalmente aos professores que se viram obrigados a usarem os recursos tecnológicos digitais de maneira instantânea e, muitas vezes, sem a devida formação. Por isso, as discussões sobre a cibercultura na docência estão presentes neste artigo, e elas não começaram no presente momento por causa da atual realidade, mas se intensificaram a partir da emergência do ensino remoto.

Segundo Lemos (2008, p. 15), "a cultura contemporânea, associada às tecnologias digitais (ciberespaço, simulação, tempo real, etc.), vai criando uma nova relação entre a técnica e a vida social que chamaremos de cibercultura", momento em que essa cultura revoluciona a comunicação em todos os espaços, inclusive os escolares. Conforme Santos (2015), cabe aos docentes se apropriarem de questões que envolvam as gerações "Y" e "Z", caracterizadas pelas práticas de compartilhamento, colaboração, interatividade, liberação de autorias e conectividade. As tecnologias digitais permitem a inovação em sala de aula, despertando o interesse e a criatividade dos alunos, por isso os professores são os responsáveis pela motivação ao conhecimento, e assume-se que os paradigmas educacionais precisam ser reconfigurados para a construção de uma educação voltada à cibercultura.

O projeto de extensão aconteceu por meio de oficinas com datas preestabelecidas, realizadas em 10 encontros ao longo do segundo semestre de 2018, com duração média de 2 horas no turno vespertino. As oficinas foram organizadas a fim de constituírem aprofundamento teórico referente aos conceitos de cibercultura na formação docente, bem como a análise de práticas pedagógicas complementando tais saberes. Cada oficina trazia assuntos de acordo com as demandas do grupo participante, permitindo, assim, a troca de experiências para sua 
autoformação. A perspectiva da autoformação (JOSSO, 2004) é assumida como um princípio central para a formação docente. A seguir, apresentaremos os percursos métodológicos do projeto, os relatos e as análises sobre as oficinas, e as considerações finais.

\section{Percursos metodológicos}

Iniciamos o projeto com leituras de autoras da área, aprofundando os conhecimentos acerca do conceito de ubiquidade e retomando os conceitos de cibercultura na formação docente (SANTAELLA, 2013; SANTOS, 2015). Em um segundo momento, criamos uma enquete no Facebook, na intenção de perceber qual o melhor dia da semana para que as pessoas pudessem participar das oficinas, sendo escolhida a quinta-feira para a sua realização. A partir disso, organizamos as datas, os materiais de divulgação e a sua exposição na Universidade, de modo que fomos nas salas de aula e distribuímos panfletos, bem como compartilhamentos nas redes sociais e socializamos o material com as escolas do município de Jaguarão.

O conceito de "experiência formadora" foi orientador das práticas desenvolvidas no projeto, pois a ideia era não oferecer uma formação pronta, mas oportunizar que dúvidas e demandas do grupo participante orientassem o planejamento das atividades. Segundo Josso (2004, p. 39), o que torna uma experiência formadora

\footnotetext{
[...] é uma aprendizagem que articula, hierarquicamente: saber-fazer e conhecimentos, funcionalidade e significação, técnicas e valores num espaço-tempo que oferece a cada um a oportunidade de uma presença para si e para a situação, por meio da mobilização de uma pluralidade de registros.
}

Conforme mencionado anteriormente, as oficinas aconteceram em datas prestabelecidas, de maneira que totalizassem 10 encontros entre os meses de julho e dezembro de 2018, com duração de 2 horas, no período vespertino. Cada encontro trazia uma temática diferente acerca das tecnologias digitais relacionadas ao trabalho pedagógico, de acordo com as solicitações do grupo participante. As oficinas aconteciam em forma de roda de conversas, que, segundo Warschauer (1994, p. 109), "desempenha um papel importante no aprendizado da atitude interdisciplinar na medida em que exercita a espera para ouvir o outro e a própria fala inscrita em contexto coletivo", criando um espaço aberto ao diálogo, discussões e compartilhamentos de vivências. Contamos, ainda, com o apoio de outros docentes, com vistas a enriquecer as oficinas e possibilitar a troca de experiências, bem como momentos práticos para complementar as abordagens teóricas, assumindo, assim, a possibilidade de constituição de experiências formadoras (JOSSO, 2004). 
A Tabela 1, a seguir, especifica a ordem das oficinas com suas respectivas datas, temas e ministrantes.

Tabela 1 - Cronograma final das oficinas

\begin{tabular}{|c|c|c|c|}
\hline OFICINAS & DATAS & TEMA & MINISTRANTE(S) \\
\hline $1^{\mathrm{a}}$ & $05 / 07 / 2018$ & $\begin{array}{l}\text { O trabalho docente na cibercultura: o } \\
\text { que tematizar? }\end{array}$ & $\begin{array}{l}\text { Prof }^{\mathrm{a}} \text {. Dra }{ }^{\mathrm{a}} \text {. Juliana Brandão Machado } \\
\text { (coordenadora do projeto de extensão) }\end{array}$ \\
\hline $2^{\mathrm{a}}$ & $16 / 08 / 2018$ & $\begin{array}{l}\text { As tecnologias digitais no cotidiano } \\
\text { da escola }\end{array}$ & $\begin{array}{l}\text { Prof }^{\mathrm{a}} \text {. Dr }{ }^{\mathrm{a}} \text {. Juliana Brandão Machado } \\
\text { (coordenadora do projeto de extensão) }\end{array}$ \\
\hline $3^{\mathrm{a}}$ & $23 / 08 / 2018$ & Conceituando a cibercultura & $\begin{array}{l}\text { Prof }^{\mathrm{a}} \text {. Dr }{ }^{\mathrm{a}} \text {. Juliana Brandão Machado } \\
\text { (coordenadora do projeto de extensão) }\end{array}$ \\
\hline $4^{\mathrm{a}}$ & $06 / 09 / 2018$ & $\begin{array}{l}\text { Ferramentas de compartilhamento e } \\
\text { colaboração (Google Drive) }\end{array}$ & $\begin{array}{l}\text { Prof }^{\mathrm{a}} \text {. Dr }{ }^{\mathrm{a}} \text {. Cláudia Perez (docente do } \\
\text { Campus Jaguarão) }\end{array}$ \\
\hline $5^{\mathrm{a}}$ & $27 / 09 / 2018$ & $\begin{array}{l}\text { Planejamento com recursos } \\
\text { tecnológicos digitais para uso em sala } \\
\text { de aula }\end{array}$ & $\begin{array}{l}\text { Prof }^{a} \text {. Dr }{ }^{\mathrm{a}} \text {. Juliana Brandão Machado } \\
\text { (coordenadora do projeto de extensão) }\end{array}$ \\
\hline $6^{\mathrm{a}}$ & $11 / 10 / 2018$ & $\begin{array}{l}\text { Experiências mídia-educativas na } \\
\text { escola }\end{array}$ & $\begin{array}{l}\text { Prof }^{\mathrm{a}} \text {. Dr }{ }^{\mathrm{a}} \text {. Paula Bianchi (docente do } \\
\text { Campus Jaguarão) }\end{array}$ \\
\hline $7^{\mathrm{a}}$ & $18 / 10 / 2018$ & $\begin{array}{l}\text { Experiências com as tecnologias } \\
\text { digitais em sala de aula }\end{array}$ & $\begin{array}{l}\text { Prof }{ }^{\mathrm{a}} \text {. Tatiane Melgares (docente na } \\
\text { rede municipal e estadual de Jaguarão) }\end{array}$ \\
\hline $8^{\mathrm{a}}$ & $29 / 11 / 2018$ & Software Audacity (editor de áudio) & $\begin{array}{l}\text { Prof }^{\mathrm{a}} \text {. Dr }{ }^{\mathrm{a}} \text {. Cláudia Perez (docente do } \\
\text { Campus Jaguarão) }\end{array}$ \\
\hline $9^{a}$ & $06 / 12 / 2018$ & $\begin{array}{l}\text { Explorando aplicativos digitais como } \\
\text { ferramentas de ensino e aprendizagem }\end{array}$ & $\begin{array}{l}\text { Prof }^{a} \text {. Paula Brum e Prof }{ }^{a} \text {. Janaína } \\
\text { Martins (Mestras em Educação pela } \\
\text { Unipampa, Campus Jaguarâo) }\end{array}$ \\
\hline $10^{\mathrm{a}}$ & $13 / 12 / 2018$ & Retrospectiva e avaliação final & $\begin{array}{l}\text { Grazielle de Souza Brandão (bolsista } \\
\text { do projeto de extensão) }\end{array}$ \\
\hline
\end{tabular}

Fonte: Autores 
Vale ressaltar que as oficinas foram elaboradas de acordo com as demandas suscitadas no trabalho com o grupo, através dos registros de avaliação em cada oficina. A seguir, os relatos e análises sobre as oficinas e as considerações finais.

\section{Desenvolvendo o projeto: relato e análises das oficinas}

No dia 5 de julho de 2018, iniciamos os encontros com a primeira oficina, contando com a presença de 20 participantes inscritos previamente via $e$-mail, entre eles estudantes dos cursos de licenciatura em Letras, História e Pedagogia da UNIPAMPA. A oficina intitulada "O trabalho docente na cibercultura: o que tematizar?" trouxe, em seu primeiro momento, a apresentação do grupo organizador e dos participantes, e teve por objetivo ser um encontro voltado à abordagem inicial de alguns conceitos referentes às tecnologias digitais e sua importância no contexto educacional, vivências e uma dinâmica reflexiva sobre a ligação das pessoas aos seus aparelhos tecnológicos. Segundo Santos (2015, p. 49),

As tecnologias digitais permitem que possamos levar para a sala de aula o cinema, as artes em geral, os cotidianos, as ciências, as culturas do mundo. Não podemos esquecer que a internet é, sobretudo, o lugar do encontro e da produção do conhecimento em rede.

A dinâmica consistia em fazer com que os participantes deixassem por alguns instantes os seus recursos tecnológicos digitais em uma toalha estendida no chão, e a partir desses minutos, sem responder as mensagens no aplicativo Whatsapp, realizar alguma pesquisa no Google ou verificar o que estava acontecendo nas redes sociais; eles perceberem que os aparelhos, bem como a internet, já fazem parte do nosso cotidiano e colaboram para uma nova cultura que estamos a vivenciar. Foi oportunizado que os participantes dissessem como se sentiram em relação a essa experiência. Muitos destacaram certo nervosismo em não poder manusear o smartphone ou notebook, e refletiu-se sobre o quanto isso anuncia uma forma de cultura própria do nosso tempo, demarcada pelas instantaneidades (CASTELLS, 2003).

Ao final da oficina, pediu-se que escrevessem uma avaliação destacando alguns pontos referentes ao primeiro encontro. Alguns participantes destacaram que as reflexões acerca da cultura digital fizeram com que percebessem a importância das relações que nascem por meio dela, e que muitas vezes acabamos não as valorizando ou isso passa despercebido em nosso cotidiano. Um participante destacou que gostou de "ver vários inscritos em uma roda de conversa com o espaço aberto para a exposição de ideias e dúvidas". 
A maioria trouxe como destaque a discussão sobre o conceito de cibercultura, afirmando que "as informações foram de muita qualidade", sendo que houve compreensão, já que não tinham conhecimento algum sobre a palavra, salientando, ainda, a importância dessa nova cultura também nas escolas. Gostaram da dinâmica que envolvia os aparelhos tecnológicos digitais e, assim, acabaram percebendo o quanto estão ligados a eles, pois alguns minutos foram suficientes para gerar um certo desconforto por estarem distantes das redes. Vale ressaltar que o registro avaliativo solicitado aos participantes no primeiro encontro foi realizado também nas demais oficinas, a fim de colaborar com o replanejamento das atividades e como forma de avaliação final do projeto de extensão.

Após o recesso de férias da universidade, retornamos com a segunda oficina, no dia 16 de agosto de 2018, intitulada "As tecnologias digitais no cotidiano da escola", contando com a presença de 19 alunos da licenciatura e um professor de matemática da rede básica de ensino. A ideia deste encontro foi fazer com que os participantes descrevessem uma situação em sala de aula envolvendo as tecnologias digitais de forma positiva ou negativa, e na troca com os demais socializassem o que fariam enquanto docentes naquela situação. De acordo com a avaliação referente à oficina, a maioria destacou que essa atividade trouxe muitas reflexões e que a interação com os colegas foi essencial para o desenvolvimento e a troca de opiniões.

Destacaram o depoimento do professor participante e a forma como ele utiliza as tecnologias digitais em suas aulas, gravando-as e, posteriormente, disponibilizando-as em seu canal no YouTube, enriquecendo a conversa com as experiências que a prática proporciona. Relataram, ainda, a importância de os docentes abrirem-se para as novas possibilidades de ensino, libertando-se dos modelos tradicionais e percebendo a cibercultura como um complemento positivo na aquisição de conhecimentos, em que "qualquer aprendiz pode trazer, para o mestre, informações que este não detém" (SANTAELLA, 2013, p. 307). Neste sentido, as ideias mencionadas pelo grupo se alinham ao pensamento de Santos $(2015$, p. 29), pois "de nada adiantam as potencialidades comunicacionais favoráveis à educação em nosso tempo se o professor se encontra alheio ao que se passa no atual cenário sociotécnico", prejudicando, assim, o desenvolvimento e a autonomia dos alunos.

A terceira oficina aconteceu no dia 23 de agosto de 2018, com a presença de 16 participantes, sendo 15 alunos de licenciatura e 1 professor da rede básica, e deu continuidade ao segundo encontro, porém, abordaram-se alguns conceitos relacionados à cibercultura, como ciberespaço, inclusão digital, interatividade, mobilidade e ubiquidade.

Em tempos de cibercultura avançada, a mobilidade ganha potência por conta da sua conexão com o ciberespaço. $\mathrm{Na}$ era da mobilidade com conexões generalizadas em rede, podemos compartilhar e acessar simultaneamente vários lugares. Estamos diante da potência da ubiquidade (SANTOS, 2015, p. 32-33). 
Neste encontro, os participantes destacaram como de fundamental importância o aprofundamento dos conceitos por meio dos slides, considerando-os essenciais para a compreensão de alguns pontos sobre os quais restavam dúvidas. Uma participante disse: "gosto muito das oficinas e as palavras da professora me fazem pensar muito sobre o assunto a cada situação destacada". Acrescentaram que "as oficinas estão bem elaboradas e a proposta segue com seu objetivo".

O quarto encontro aconteceu no dia 6 de setembro de 2018 e contou com a presença de 8 participantes, todos alunos de licenciatura. Esta oficina, intitulada "Ferramentas de compartilhamento e colaboração (Google Drive)", teve a participação da professora Cláudia Perez, docente da UNIPAMPA, Campus Jaguarão. A abordagem foi direcionada ao manuseio de diversas ferramentas do Google, proporcionando uma aprendizagem acerca de recursos existentes para serem utilizados no planejamento e na realização das aulas. Segundo Bonilla e Oliveira (2011), um dos grandes problemas enfrentados nas escolas, atualmente, é a falta de formação continuada aos professores para que eles atendam às expectativas dos alunos no que tange à utilização de recursos tecnológicos digitais em sala de aula. $\mathrm{O}$ uso se torna meramente instrumental, ir à sala de informática realizar algumas pesquisas não vai ao encontro dos princípios da cibercultura, que tratam da importância do compartilhamento e da colaboração nas redes pelos sujeitos, de forma livre e aberta (LÉVY, 2007).

Alguns participantes destacaram na avaliação, ao final da oficina, o fato de que muitas vezes utilizamos diariamente páginas na internet e desconhecemos suas várias opções de trabalho e, principalmente, meios que acabam facilitando também as produções acadêmicas. Apontaram também a importância dos encontros práticos para dar embasamento às teorias.

A quinta oficina, "Planejamento com recursos tecnológicos digitais para uso em sala de aula", aconteceu no dia 27 de setembro de 2018 e teve a presença de 9 participantes, todos alunos de licenciatura da UNIPAMPA. A ideia para este encontro era de que os participantes desenvolvessem uma atividade baseada na escolha de um nível de ensino da Educação Básica, um tema ou conteúdo a ser abordado com os alunos, além de um recurso tecnológico digital para uso em sala de aula. A partir dessas escolhas, deveriam elaborar uma proposta pedagógica, descrevendo como realizariam a abordagem da temática com a tecnologia digital.

A partir das atividades apresentadas pelos participantes, as necessárias discussões sobre pensar em novos planos de aula voltados à cibercultura desencadearam ideias criativas e possíveis de serem colocadas em prática, de acordo com as realidades escolares conhecidas, especialmente das redes públicas de ensino. Um participante teve a ideia de utilizar os sites que possibilitam visitas a determinados momentos da História para que os alunos possam observar, facilitando suas aprendizagens. Houve, ainda, a apresentação de um vídeo que trata sobre a metodologia de ensino, que por muitas vezes se torna repetitiva, e que mesmo levando novidades à escola com os recursos tecnológicos digitais, alguns professores não mudam as estratégias, condicionando os alunos a uma educação que não prioriza a busca autônoma por saberes. 
Conforme as avaliações ao final da oficina, pôde-se perceber que as reflexões acerca do vídeo apresentado foram consideradas fundamentais para compreender o que, de fato, acontece em muitas instituições escolares. Uma participante, ao se referir a este momento do encontro, diz observar que: "existe a evolução, mas alguns professores seguem resistentes ao uso dos recursos em sala de aula por diversos motivos". Conforme Pretto (2011, p. 110), "as tecnologias digitais precisam ser entendidas pelas escolas como elementos de cultura, e não apenas como aparatos tecnológicos que ilustram ou facilitam os processos escolares". Portanto, a cibercultura presente na educação oportuniza a produção de múltiplos conhecimentos aliados ao nosso tempo e às demandas contemporâneas.

Os participantes destacaram que a dinâmica aplicada nesse encontro gerou várias ideias para aplicabilidade com os alunos até mesmo nos estágios supervisionados dos cursos de licenciatura, considerando as trocas de experiências essenciais para o desenvolvimento posterior de atividades.

A sexta oficina aconteceu no dia 11 de outubro de 2018 e contou com a presença de 5 alunos de licenciatura da instituição. O tema "Experiências mídia-educativas na escola" foi apresentado pela professora Paula Bianchi, docente da UNIPAMPA, Campus Jaguarão. A proposta inicial foi a apresentação das experiências de uma pesquisa de Mestrado de um orientando da professora em relação ao jornal na escola, tendo como embasamento os comceitos referentes à "mídia-educativa" e "educomunicação", bem como assuntos que permeiam a cultura digital, os recursos tecnológicos digitais utilizados durante suas práticas na educação e sua relação com a criação de uma rádio em outro campus da universidade. Dessa maneira, o grupo teve a oportunidade de conhecer ações que incluem diferentes recursos tecnológicos nas práticas educativas escolares, tanto na Educação Básica quanto na Educação Superior.

A partir dos conhecimentos adquiridos e compartilhados nesta oficina, foi possível estabelecer relações com o que Santaella (2010) chama de cinco gerações tecnológicas que envolvem a linguagem e a comunicação, mais especificamente com três delas. A primeira geração foi denominada pela autora como "Tecnologias do reprodutível" e envolve os recursos do cinema, foto e jornal para expor as informações ao público.

A segunda geração, "Tecnologias da difusão", traz a televisão e o rádio como os responsáveis pela rápida absorção de culturas diferentes e expansão nos locais até então de difícil acesso. Por outro lado, o uso de smartphones e internet superou a marca de 50 milhões de pessoas conectadas em um período de 4 anos, enquanto a televisão levou 13 anos e o rádio cerca de 38 anos para alcançar o mesmo número de público (PRETTO; PINTO, 2006). Isso demonstra a rapidez com que a cibercultura passou a fazer parte das nossas vidas.

A terceira geração, denominada "Tecnologias do disponível", volta-se à ideia de uma "cultura das mídias" (SANTAELLA, 2010), fazendo com que as pessoas busquem, de maneira 
individual, por recursos próprios, de acordo com suas especificidades. Por exemplo, a televisão a cabo, uma rede composta por canais que vão ao encontro do que o seleto público espera encontrar quando os contrata.

Dessa forma, perceberam-se as relações com os assuntos abordados no sexto encontro, principalmente para que se compreenda a evolução no campo das tecnologias digitais e dos recursos disponíveis a serem usados pelos professores, visando "novas educações" (PRETTO; PINTO, 2006). Os participantes dessa oficina expressaram, por meio da avaliação, o quanto gostaram dos relatos de experiências apontados pela professora em sua trajetória. Destacaram, ainda, o diálogo acerca da cultura digital e do quanto a realidade escolar está longe do que deveria ser e, consequentemente, os estudantes são os mais prejudicados com a escassez dos recursos tecnológicos digitais para uso em sala de aula, ou até mesmo por diversos motivos que permeiam a vida dos professores, não fazendo uso das tecnologias digitais também na educação.

A sétima oficina, "Experiências com as tecnologias digitais em sala de aula", ocorreu no dia 18 de outubro de 2018 e teve a participação de 8 alunos de licenciatura da UNIPAMPA. Esse encontro contou com a presença da professora Tatiane Melgares, docente das redes municipal e estadual de Jaguarão/RS. A proposta era que ela apresentasse a pesquisa realizada no Mestrado Profissional em Educação da UNIPAMPA, cuja intervenção foi uma formação continuada ofertada aos professores sobre o uso de recursos tecnológicos digitais em sala de aula, realizada na escola onde ela atuava como orientadora educacional. Essa oficina teve a intenção de trazer algumas ideias práticas para que os docentes em formação se apropriassem das possibilidades de trabalho na escola "real", e com isso pensassem em novas formas de utilizar tais recursos em sala de aula, seja em seus estágios supervisionados ou, posteriormente, na atuação profissional.

Os participantes desse encontro destacaram que gostaram muito da participação da professora Tatiane, pois a sua atuação profissional na escola pública permite que ela apresente a sua realidade e os recursos tecnológicos digitais disponíveis. Gostaram, principalmente, do fato de que a intervenção feita por ela gerou oficinas para os professores dentro da própria escola, facilitando a participação de todos e colaborando para a construção de novas métodologias de ensino. Os participantes ressaltaram a importância do contato com os professores nas oficinas e, por meio dos diálogos, conhecerem as realidades escolares. Uma participante enfatizou que:

os momentos teóricos foram fundamentais e as discussões em relação às práticas auxiliam na elaboração de ideias sobre quais recursos utilizar em determinados componentes e de que maneira fazer os alunos participarem ativamente da sua própria aprendizagem.

A oitava oficina aconteceu no dia 29 de novembro de 2018 e contou com a presença de 13 alunos de licenciatura da instituição. O tema "Software Audacity (editor de áudio)" foi apresentado pela professora Cláudia Perez, docente da UNIPAMPA, Campus Jaguarão. Esse 
encontro teve por objetivo ensinar algumas funcionalidades do software Audacity, um editor de áudios gratuito com possibilidades de gravação, conversão e união de arquivos. Sendo assim, a oficina foi realizada no laboratório de informática do campus, e os participantes puderam experimentar alguns recursos que servirão para embasar novas metodologias em suas práticas educacionais, pois não basta ter acesso às tecnologias digitais, é necessário pensar e discutir sobre maneiras de usá-las, promovendo situações de ensino e aprendizagem aos alunos.

O destaque entre as avaliações dos participantes, ao final da oficina, foi para a aprendizagem de um editor desconhecido para muitos, destacando sua relevância e praticidade. Elogiaram a participação da professora Cláudia, bem como sua atenção com todos e a explicação detalhada sobre cada recurso do Audacity. Por fim, parabenizaram o fato de as oficinas serem mais práticas, e de acordo com um participante:

dessa forma foi possível trabalhar diretamente com os recursos tecnológicos digitais e as ferramentas ofertadas, trocando ideias e informações, principalmente pensando em como desenvolver aulas utilizando tais programas.

No dia 6 de dezembro de 2018, foi realizada a nona oficina do projeto, com a presença de 9 alunos de licenciatura da UNIPAMPA. Esse encontro contou com as participações das professoras Paula Brum e Janaína Martins, mestras em Educação pelo Programa de Pós-Graduação em Educação da UNIPAMPA. A proposta se baseava em apresentar alguns aplicativos com viés pedagógico a serem utilizados em sala de aula. Em um primeiro momento, as professoras apresentaram o Socrative, aplicativo voltado aos docentes para elaboração de avaliações, jogos de perguntas e respostas, entre outras funções; logo, os participantes utilizaram o aplicativo Kahoot, um jogo de questões com interação entre a tela por meio do projetor multimídia e o celular; por fim, conheceram o Storybird, um site que permite a criação de livros ilustrados.

O uso de aplicativos por meio da cultura digital, visando novos caminhos para a educação, favorece uma aprendizagem em grupo de forma colaborativa. Percebe-se que, de maneira geral, os estudantes manifestam interesse em jogos que instiguem seus conhecimentos e oportunizem desafios a serem superados. Segundo Santos e Weber (2013, p. 58),

a criação de práticas pedagógicas baseadas em aprendizagem móvel, na perspectiva da mobilidade, conectividade e ubiquidade, revela a potencialidade para a educação dos dispositivos móveis e do digital em rede. Tal potência é vista não como forma de substituição da aprendizagem formal, mas como compreensão da prática pedagógica articulada a uma prática social, datada e situada como uma produção histórica e cultural. 
A partir da importância de se discutir sobre o uso dos recursos tecnológicos digitais como elementos complementares e não substitutivos à educação formal, informal e não formal (SANTAELLA, 2010), pensou-se no tema desta oficina para reforçar as concepções acerca das potencialidades da relação entre a cibercultura e a educação.

De acordo com a avaliação ao final da oficina, o primeiro destaque observado foi pela novidade, pois os participantes não conheciam nenhum dos aplicativos apresentados e isso gerou interesse e curiosidade acerca de outras possibilidades. Gostaram do fato de a oficina ser prática e interativa, aprendendo um pouco mais sobre ferramentas digitais para uso pedagógico. Por fim, elogiaram as ministrantes e a troca de informações essenciais à formação docente.

A décima oficina aconteceu no dia 13 de dezembro de 2018 e contou com a presença de 10 participantes, todos alunos de licenciatura da Instituição. A proposta para o último encontro baseava-se em retomar as 9 oficinas por meio de slides com a data, o tema e algumas fotos, e propor aos participantes uma discussão avaliativa sobre as oficinas, retomando seus conceitos, ideias e aspectos de destaque de cada encontro. A roda de conversas foi mediada pela bolsista de iniciação à extensão do projeto.

De acordo com os registros avaliativos dos participantes sobre as oficinas e o projeto em si, diversos pontos foram destacados, e no processo de autoformação, as aprendizagens sobre novas ferramentas e recursos tecnológicos digitais a serem utilizados em sala de aula fizeram com que as oficinas proporcionassem uma amplitude de ideias e trocas de conhecimentos. Segundo Nóvoa (1997, p. 26), "a troca de experiências e a partilha de saberes consolidam espaços de formação mútua". Dessa forma, é a partir das relações com os outros que se constroem o conhecimento e as experiências formadoras.

Os encontros em forma de roda de conversas permitiram a visão acerca de todos os participantes e suas opiniões diferentes, colaborando com o desenvolvimento pessoal e acadêmico. Conforme apontou uma participante: "os encontros contribuíram muito, pois posso refletir com mais criticidade sobre as tecnologias tanto na vida pessoal quanto em âmbito educacional". Destacaram, ainda, que as oficinas oportunizaram a reflexão sobre novas práticas pedagógicas, visto que os assuntos abordados foram muito pertinentes e vão ao encontro da atualidade e da necessidade de se repensar a educação dinamizando mais as aulas, pois segundo Freire (1996, p. 43), "pensando criticamente a prática de hoje ou de ontem é que pode melhorar a próxima prática". Dessa forma, as oficinas contribuíram em diversos aspectos, possibilitando novas concepções acerca dos processos educacionais, o uso dos recursos tecnológicos digitais e a necessária discussão permanente na formação acadêmica dos professores sobre a potencialidade da cibercultura na educação. 
É importante destacar que todos os participantes, ao final de cada oficina, realizavam as avaliações escritas, expressando suas opiniões sobre as discussões, assim como ideias para os próximos encontros. $\mathrm{O}$ grupo teve início com 20 participantes, entre eles alunos dos cursos de licenciatura de História, Letras e Pedagogia da UNIPAMPA, e 1 professor de Matemática da rede básica. Alguns participantes deixaram de comparecer aos encontros por incompatibilidades de horário, mas, em média, tinha-se nas oficinas cerca de 10 participantes, até o último encontro.

A partir da análise realizada sobre as avaliações dos participantes em relação ao projeto, destacou-se a importância na continuidade das discussões para a formação de professores, tanto inicial quanto continuada, e isso acena para a proposição de outras edições do projeto de extensão. A cibercultura na docência se mantém como um tema emergente e o uso dos recursos tecnológicos digitais permanecerá entre os assuntos que envolvem o trabalho dos professores na contemporaneidade.

\section{Considerações finais}

Ao iniciarmos este projeto de extensão, aspiramos por encontros voltados aos professores em formação inicial e continuada para sua autoformação, objetivando desenvolver oficinas teóricas e práticas, discutindo a relação entre docência e cibercultura. Cada oficina desenvolvida proporcionou momentos de aprendizado, trocas de experiências e reflexões acerca dessa nova cultura na educação e suas diversas formas de imersão nas escolas. A cibercultura está presente em todos os espaços e é preciso romper os paradigmas que impedem o uso de recursos tecnológicos digitais, oportunizando, assim, melhores práticas pedagógicas e beneficiando os alunos em seus processos educacionais.

Sendo assim, o objetivo principal do projeto se estabeleceu em cada encontro, por meio de diálogos e reflexões que enfatizaram a importância dos docentes em formação e dos professores da rede de ensino, ao preocuparem-se com as inovações advindas de um contexto vivenciado por todos e que colabora, em seus diversos aspectos, com a educação, qualificando o ensino.

Espera-se que esses espaços de formação possam constituir momentos de discussão permanente sobre a docência na cibercultura, destacando, tal como preconizou Lévy (2007), a potencialidade positiva da cibercultura, sobretudo no contexto escolar. Isso denota a construção de outros modelos pedagógicos, demarcados pelo uso de recursos tecnológicos digitais, que certamente continuarão a fazer parte do cotidiano escolar no pós-pandemia. 
Consideramos que o projeto de extensão contribuiu para a formação docente, em vista de que os professores precisam conscientizar-se de que, entre seus vários papéis, necessitarão inovar os ambientes educacionais, pois estão inseridos em uma era digital em que os alunos participam ativamente da sua própria aprendizagem. Por isso, através das discussões e práticas realizadas nas oficinas, buscamos proporcionar uma amplitude de ideias, auxiliando-os na elaboração de novas práticas pedagógicas, por meio de softwares educativos, produção de materiais, programas de ensino, planos de aulas com base nos recursos tecnológicos digitais disponíveis conforme a realidade escolar, contribuindo, assim, com a constituição de uma docência para a cibercultura.

\section{Referências}

BONILLA, Maria Helena Silveira; OLIVEIRA, Paulo Cezar Souza de. Inclusão digital: ambiguidades em curso. In: BONILLA, Maria Helena Silveira; PRETTO, Nelson de Luca (org.). Inclusão digital: polêmica contemporânea. Salvador: EDUFBA, 2011.

CASTELLS, Manuel. A Galáxia da Internet. Rio de Janeiro: Zahar, 2003.

FREIRE, Paulo. Pedagogia da autonomia: saberes necessários à prática educativa. São Paulo: Paz e Terra, 1996.

JOSSO, Marie-Christine. Experiências de vida e formação. São Paulo: Cortez, 2004.

LEMOS, André. Cibercultura, tecnologia e vida social na cultura contemporânea. Porto Alegre: Sulina, 2008.

LÉVY, Pierre. Cibercultura. São Paulo: Ed.34, 2007.

NÓVOA, Antonio (coord.). Os professores e sua formação. Lisboa-Portugal: Dom Quixote, 1997.

PRETTO, Nelson de Luca; PINTO, Cláudio da Costa. Tecnologias e novas educações. Revista Brasileira de Educação, v. 11, n. 31, p. 19-30, jan./abr. 2006.

PRETTO, Nelson de Luca. O desafio de educar na era digital: educações. Revista Portuguesa de Educação. v. 24, n. 1, p. 95-118, 2011. CIEd - Universidade do Minho. 
SANTAELLA, Lucia. A aprendizagem ubíqua substitui a educação formal? ReCeT:

Revista de Computação e Tecnologia da PUC-SP, São Paulo, v. 2, n. 1, p. 17-22, 2010.

SANTAELLA, Lucia. Comunicação ubíqua: repercussões na cultura e na educação. São Paulo: Paulus, 2013.

SANTOS, Edméa Oliveira dos; WEBER, Aline. A criação de atos de currículo no contexto de espaços intersticiais. Teccogs, n. 7, p.42-60, jan./jun. 2013. Disponível em:

http://www4.pucsp.br/pos/tidd/teccogs/artigos/2013/edicao 7/3-

criacao de atos decurriculo em espacos intersticiais-edmea santos-aline weber.pdf Acesso em: 29 nov. 2019.

SANTOS, Edméa Oliveira dos. Pesquisa Formação na Cibercultura. Rio de Janeiro: Whitebooks, 2015.

WARSCHAUER, Cecília. Refletindo sobre a Interdisciplinaridade. Ensino Em Re-Vista, v. 3, n. 1, jan./dez. 1994. Disponível em:

http://www.seer.ufu.br/index.php/emrevista/article/view/7797 Acesso em: 29 nov. 2019. 